\title{
Fatores socioeconômicos que influenciam a percepção de adolescentes sobre sexualidade, maternidade e aborto
}

Socioeconomic factors that influence adolescents' perception of sexuality, motherhood and abortion Factores socioeconómicos que influyen en la percepción de las adolescentes sobre la sexualidad, la maternidad y el aborto

\section{Resumo}

O objetivo foi analisar as percepções sobre sexualidade, maternidade e aborto, segundo fatores socioeconômicos em adolescentes de 15 a 19 anos, estudantes do ensino médio, na Região Metropolitana da Grande Vitória - Espírito Santo, Brasil. Estudo transversal de base escolar, com 2.292 estudantes, realizado em 2016/2017, por meio de entrevista estruturada. Utilizou-se o instrumento "Questionário de Valores e Crenças sobre Sexualidade, Maternidade e Aborto", que possui cinco dimensões: prazer, afetividade, reprodução, maternidade e aborto. Para as análises, utilizou-se: média, desvio-padrão, ANOVA e regressão linear múltipla. Verificou-se predominância de concordância para as percepções sobre as funções da sexualidade, desvinculação da maternidade como função principal da condição feminina e percepções negativas sobre aborto. Na regressão, a dimensão maternidade foi a mais explicada pelos fatores socioeconômicos $\left(\mathrm{R}^{2}=6,7 \%\right)$ : idade $18 / 19$ anos $(\beta=0,154)$, sexo masculino $(\beta=0,154), 2^{\circ}$ e $3^{\circ}$ anos do ensino médio $(\beta=-0,118 ;-0,172)$, situação conjugal $(\beta=-0,341)$, ter trabalho remunerado $(\beta=0,113)$, chefe da família com ensino médio ou superior $(\beta=-0,234 ;-0,246)$ e renda total da família $>3$ salários $(\beta=-0,234)$. A percepção dos adolescentes é influenciada por fatores socioeconômicos, sendo as desigualdades socioeconômicas importantes marcadores para essas percepções.

Palavras-chave: Sexualidade; Gravidez na adolescência; Aborto; Condições sociais.

\begin{abstract}
The aim was to analyze perceptions about sexuality, motherhood and abortion, according to socioeconomic factors in adolescents aged 15 to 19 years, high school students, in the Greater Vitoria Metropolitan Region - Espirito Santo, Brazil. Cross-sectional school-based study with 2,292 students, carried out in 2016/2017, through a structured interview. The instrument "Questionnaire of Values and Beliefs about Sexuality, Maternity and Abortion" was used, which has five dimensions: pleasure, affectivity, reproduction, motherhood and abortion. For the analyzes, we used: mean, standard deviation, ANOVA and multiple linear regression. There was a predominance of agreement for the perceptions about the functions of sexuality, disconnection from motherhood as the main function of the female condition and negative perceptions about abortion. In the regression, the maternity dimension was the most explained by socioeconomic factors $\left(\mathrm{R}^{2}=6.7 \%\right)$ : age $18 / 19$ years $(\beta=0.154)$, male gender $(\beta=0.154)$, 2nd and 3rd years of high school $(\beta=-0.118 ;-0.172)$, marital status $(\beta=-0.341)$, having paid work $(\beta=0.113)$, head of the family with secondary education or higher $(\beta=-0.234 ;-0.246)$ and total family income $>3$ wages $(\beta=-0.234)$. Adolescents'
\end{abstract}


perceptions are influenced by socioeconomic factors, with socioeconomic inequalities being important markers for these perceptions.

Keywords: Sexuality; Pregnancy in adolescence; Abortion; Social conditions.

\begin{abstract}
Resumen
El objetivo fue analizar las percepciones sobre sexualidad, maternidad y aborto, según factores socioeconómicos, en adolescentes de 15 a 19 años, estudiantes de secundaria, en la Región Metropolitana de Gran Vitória - Espírito Santo, Brasil. Estudio transversal de carácter escolar con 2.292 alumnos, realizado en 2016/2017, mediante entrevistas estructuradas. Se utilizó el instrumento "Cuestionario de Valores y Creencias sobre Sexualidad, Maternidad y Aborto", el cual tiene cinco dimensiones: placer, afecto, reproducción, maternidad y aborto. Para los análisis utilizamos: media, desviación estándar, ANOVA y regresión lineal múltiple. Predominó el acuerdo para las percepciones sobre las funciones de la sexualidad, el desapego de la maternidad como función principal de la condición femenina y las percepciones negativas sobre el aborto. En la regresión, la dimensión de maternidad fue la más explicada por factores socioeconómicos $\left(\mathrm{R}^{2}=6,7 \%\right)$ : edad $18 / 19$ años $(\beta=0,154)$, sexo masculino $(\beta=0,154)$, 2 ${ }^{\circ}$ y $3{ }^{\circ}$ de secundaria $(\beta=-0,118 ;-0,172)$, estado civil $(\beta=-0,341)$, tener un trabajo remunerado $(\beta=0,113)$, jefe de familia con educación secundaria o superior $(\beta=-0,234 ;-0,246)$ e ingreso familiar total $>3$ salarios $(\beta=-0,234)$. La percepción de los adolescentes está influenciada por factores socioeconómicos y las desigualdades socioeconómicas son marcadores importantes de estas percepciones.
\end{abstract}

Palabras clave: Sexualidad; Embarazo en adolescencia; Aborto; Condiciones sociales.

\title{
1. Introdução
}

A compreensão da sexualidade humana implica em conhecimento do contexto social, familiar e individual. Entretanto, o modo como os indivíduos organizam as suas experiências sexuais resulta da forma como vivenciam os problemas de trato íntimo, considerando as questões morais e éticas do grupo social em que estão inseridos (Carvalho, Rodrigues \& Medrado, 2005; Angelo et al. 2021). Isso se consolida principalmente na adolescência.

Os papéis sociais da mulher e do homem estão em transição na pós-modernidade, especialmente da mulher que tem adquirido novos papéis relacionados ao mercado de trabalho e escolarização, em detrimento de suas tradicionais funções de esposa e mãe (Pereira, 2016). Essas mudanças trouxeram também alterações aos valores atribuídos à sexualidade feminina, deixando esta, de estar vinculada apenas à reprodução. Além disso, a fase da adolescência passou a ser observada por outra perspectiva, deixando de ser a faixa etária de reprodução para ser de preparação para o mercado de trabalho (Brandão \& Heilborn, 2006).

Segundo a Organização das Nações Unidas para Educação, Ciência e Cultura (2010), os pais e as famílias têm um papel vital em moldar a forma como o adolescente compreende sua identidade social e sexual. Para isso, os responsáveis parentais devem ser capazes de abordar os aspectos físicos e comportamentais da sexualidade humana, visto que as crianças e adolescentes precisam receber informações, transformá-las em conhecimento e habilidade para fazer escolhas responsáveis sobre sexualidade, relacionamentos, prevenção de Infecções Sexualmente Transmissíveis (IST) e gravidez/parentalidade. Tudo isso em conjunto com os aparelhos institucionais de educação e saúde do estado que devem atuar no sentido da promoção da saúde sexual do adolescente.

Além das influências familiares e culturais, a saúde sexual e reprodutiva é também influenciada pela condição socioeconômica do indivíduo, caracterizando suas percepções sobre a vivência da sexualidade, maternidade e o aborto, o que num futuro próximo refletirá em chance aumentada para adoção de comportamentos de risco (Oliveira-Campos et al., 2014). Nesse sentido, os fatores socioeconômicos são importantes sinalizadores do comportamento sexual de risco, determinando o maior ou menor grau de risco para a saúde (Carvalho, 2013).

Após mais de 20 anos da Conferência Internacional sobre População e Desenvolvimento no Cairo, que propôs uma definição abrangente de saúde reprodutiva e convocou as nações a atender às necessidades educacionais dos adolescentes para que possam lidar de maneira positiva e responsável com sua sexualidade, a abordagem da saúde sexual e reprodutiva do 
adolescente como direito, continua um desafio. Sendo assim, é necessário associar a prestação de serviços de educação em sexualidade e saúde sexual e reprodutiva, construir consciência e aceitação, abordar a desigualdade de gênero, considerar as crenças, atitudes e normas e visar o período inicial da adolescência (Chandra-Mouli et al., 2015).

Portanto, compreender a sexualidade em seus diversos aspectos e, na perspectiva do adolescente, pode servir de base para melhorar a abordagem sobre saúde sexual e reprodutiva apoiando experiência sexual saudável, minimizando as consequências adversas (Fontenberry, 2013). Assim, o presente estudo teve como objetivo analisar as percepções sobre sexualidade, maternidade e aborto, segundo fatores socioeconômicos em adolescentes de 15 a 19 anos, estudantes do ensino médio, na Região Metropolitana da Grande Vitória - Espírito Santo (RMGV/ES), Brasil.

\section{Metodologia}

Estudo transversal realizado por meio de um inquérito epidemiológico de base escolar, denominado: "Vigilância a fatores de risco para doenças e agravos em adolescentes de 15 a 19 anos, na RMGV/ES” com o objetivo de mensurar a exposição dos adolescentes a diversos comportamentos de risco, doenças e agravos que podem afetar o desenvolvimento da saúde física e mental.

A amostra foi calculada assegurando a representatividade dos estudantes matriculados na RMGV-ES, 65.763 estudantes em 168 escolas. Considerou-se a prevalência de 50\% para a ocorrência de fatores de risco à saúde como a maior proporção esperada, intervalo de confiança de $95 \%$, erro padrão de 2,5\% e efeito de desenho de 1,5 resguardando a precisão de uma amostragem aleatória, resultando em um tamanho mínimo amostral de 2.252 adolescentes. Para composição das cotas amostrais municipais foi considerada a distribuição percentual dos estudantes por município da RMGV-ES, obtendo-se: Cariacica 18,8\% ( $\mathrm{n}=430)$, Fundão 2,9\% ( $\mathrm{n}=67)$, Guarapari 5,9\% ( $\mathrm{n}=136)$, Serra 22,5\% ( $\mathrm{n}=515)$, Viana 4,9\% ( $\mathrm{n}=113)$, Vila Velha 22,1 \% (n=507) e Vitória 22,9\% (n=524).

Um formulário estruturado com perguntas fechadas foi aplicado a 2.292 estudantes em 54 escolas públicas e privadas da RMGV-ES, no período de agosto de 2016 a maio de 2017. Participaram da pesquisa, estudantes do ensino médio (turno matutino ou vespertino) que não possuíam deficiência cognitiva, auditiva ou visual. O processo de investigação, contou com a participação de entrevistadores previamente treinados, e foi realizado por meio de formulário eletrônico, preenchido individualmente por cada adolescente em um notebook.

Neste estudo, foi utilizado como variáveis socioeconômicas: idade, sexo, ano do ensino médio, município de residência, situação conjugal, raça/cor, trabalho remunerado, chefe da família, grau de instrução do chefe da família, renda da família e pais separados/divorciados. Também foi aplicado o instrumento denominado: "Questionário de Valores e Crenças sobre Sexualidade, Maternidade e Aborto" (QVCSMA) que tem como principal objetivo mensurar as percepções sobre sexualidade, maternidade e aborto.1

Inicialmente, para testagem do instrumento QVCSMA, considerando todas as variáveis, foi realizado um estudo piloto com 46 adolescentes estudantes de uma escola pública do município de Vitória - ES, reaplicado no intervalo de 15 dias. Em seguida, foi aplicado Kappa ajustado pela frequência em todas as questões do instrumento QVCSMA, que variou de 0,51 a 0,87, sendo o nível de significância adotado de 5\%. O teste de McNemar foi utilizado para testar a discordância da escala QVCSMA, sendo significante apenas para os itens "um filho deve ser sempre desejado e um casal sem filhos não é completamente feliz", o que resultou em discordância significativa após a reaplicação do questionário. 
Tabela 1. Pesos fatoriais de cada item nos cinco fatores retidos, autovalores, variância explicada, após uma AFE pelo método de extração das componentes principais seguida de uma rotação Varimax com normalização de Kaiser.

\begin{tabular}{|c|c|c|c|c|c|c|}
\hline \multirow{2}{*}{ Item } & \multicolumn{5}{|c|}{ FATORES } & \multirow{2}{*}{ Comunalidades } \\
\hline & Maternidade & Aborto & Prazer & Afetividade & Reprodução & \\
\hline Todas as mulheres querem ser mães & 0,643 & 0,093 & 0,217 & 0,050 & $-0,116$ & 0,585 \\
\hline Engravidar é importante para as mulheres & 0,560 & 0,091 & 0,312 & 0,213 & $-0,008$ & 0,565 \\
\hline $\begin{array}{c}\text { A minha maior motivação para ter relações } \\
\text { sexuais é a reprodução }\end{array}$ & 0,570 & $-0,068$ & $-0,119$ & 0,347 & $-0,046$ & 0,566 \\
\hline $\begin{array}{c}\text { Uma mulher é sempre responsável por uma } \\
\text { gravidez }\end{array}$ & 0,549 & $-0,040$ & $-0,130$ & 0,299 & 0,130 & 0,526 \\
\hline Uma gravidez é sempre desejada & 0,692 & $-0,001$ & $-0,130$ & 0,187 & $-0,004$ & 0,531 \\
\hline $\begin{array}{l}\text { Ter filhos é essencial para a realização da } \\
\text { mulher }\end{array}$ & 0,743 & 0,293 & 0,102 & 0,158 & 0,037 & 0,675 \\
\hline $\begin{array}{c}\text { A maternidade valoriza o status social da } \\
\text { mulher }\end{array}$ & 0,728 & 0,167 & 0,095 & 0,168 & 0,072 & 0,601 \\
\hline Um casal sem filhos não é completamente feliz & 0,786 & 0,055 & 0,020 & 0,033 & 0,090 & 0,630 \\
\hline $\begin{array}{c}\text { Ter um filho é necessário para a minha } \\
\text { felicidade }\end{array}$ & 0,678 & 0,131 & 0,161 & 0,125 & 0,136 & 0,537 \\
\hline $\begin{array}{c}\text { As mulheres que não desejam ter filhos são } \\
\text { egoístas }\end{array}$ & 0,779 & 0,050 & 0,015 & $-0,050$ & 0,092 & 0,621 \\
\hline $\begin{array}{l}\text { O aborto pode ser prejudicial a saúde } \\
\text { psicológica da mulher }\end{array}$ & 0,140 & 0,934 & 0,005 & 0,137 & 0,060 & 0,915 \\
\hline $\begin{array}{c}\text { O aborto pode ser prejudicial a saúde física da } \\
\text { mulher }\end{array}$ & $-0,017$ & 0,770 & 0,152 & 0,166 & 0,145 & 0,664 \\
\hline $\begin{array}{l}\text { O aborto é um crime em qualquer } \\
\text { circunstância }\end{array}$ & 0,301 & 0,819 & $-0,002$ & 0,141 & 0,054 & 0,784 \\
\hline $\begin{array}{c}\text { O sexo é a forma mais íntima de comunicação } \\
\text { entre duas pessoas }\end{array}$ & 0,146 & 0,006 & 0,694 & 0,058 & 0,035 & 0,507 \\
\hline $\begin{array}{l}\text { As relações sexuais são uma forma de } \\
\text { demonstrar carinho e afeto }\end{array}$ & 0,151 & 0,040 & 0,724 & 0,122 & $-0,003$ & 0,564 \\
\hline O sexo é uma parte muito importante da vida & 0,005 & 0,054 & 0,741 & 0,102 & 0,186 & 0,597 \\
\hline É importante ter prazer na relação sexual & $-0,156$ & 0,076 & 0,620 & 0,205 & 0,284 & 0,537 \\
\hline As mulheres grávidas ficam bonitas & 0,226 & 0,134 & 0,081 & 0,568 & 0,049 & 0,500 \\
\hline $\begin{array}{l}\text { A minha principal motivação para as relações } \\
\text { sexuais é sentir-me amado(a) }\end{array}$ & 0,189 & 0,035 & 0,267 & 0,684 & 0,044 & 0,578 \\
\hline O sexo sem amor não faz sentido & 0,187 & 0,170 & 0,031 & 0,707 & 0,060 & 0,568 \\
\hline $\begin{array}{c}\text { As pessoas desejam ter filhos para os amarem } \\
\text { e serem amados por eles }\end{array}$ & 0,089 & 0,156 & 0,230 & 0,652 & 0,164 & 0,537 \\
\hline Hoje em dia só engravida quem quer & 0,236 & 0,267 & 0,021 & 0,043 & 0,676 & 0,586 \\
\hline Fazer contracepção é fácil & 0,123 & 0,034 & 0,112 & 0,047 & 0,770 & 0,624 \\
\hline $\begin{array}{c}\text { Existem vantagens e desvantagens em ter um } \\
\text { filho }\end{array}$ & $-0,110$ & $-0,003$ & 0,247 & 0,174 & 0,644 & 0,519 \\
\hline Autovalor & 6,525 & 2,830 & 1,924 & 1,308 & 1,230 & \\
\hline Variância explicada $($ Global $=57.57 \%)$ & $27,19 \%$ & $11,79 \%$ & $8,02 \%$ & $5,45 \%$ & $5,12 \%$ & \\
\hline Alfa de Cronbach & 0,884 & 0,884 & 0,716 & 0,698 & 0,591 & \\
\hline \multirow[t]{2}{*}{$\begin{array}{c}\text { Medida Kaiser-Meyer-Olkin de adequação de } \\
\text { amostragem. }\end{array}$} & 0,872 & & & & & \\
\hline & $X^{2}$ & 19308,9 & & & & \\
\hline \multirow[t]{2}{*}{ Teste de esfericidade de Bartlett } & Gl & 276 & & & & \\
\hline & p-valor & $<0,001$ & & & & \\
\hline
\end{tabular}

Fonte: Autores.

Em seguida, com os dados do estudo principal, procedeu-se a realização do estudo das propriedades psicométricas do instrumento, com a proposta da análise fatorial (AF) pelo método das componentes principais com rotação Varimax para 
agrupar as perguntas do questionário de valores e crenças sobre sexualidade, maternidade e aborto. Os fatores foram agrupados seguindo o padrão de autovalor superior a um e o total de variância explicada. O modo de extração dos fatores foi realizado pelo método de componentes principais com rotação Varimax e normalização de Kaiser (Tabela 1).

Conforme Tabela 1, a AF foi realizada utilizando os 38 itens do questionário original, mas percebeu-se pouco peso fatorial em alguns itens, assim optou-se por retirar aqueles com peso fatorial < 0,5. Portanto, o questionário final foi composto por 24 itens, em que a relação entre os itens foi explicada por cinco fatores. Para a avaliação da adequação da amostragem da AF foi realizada a medida de Kaiser-Meyer-Olkin (KMO) e para a adequação dos dados o teste de esfericidade de Bartlett. Para verificar a confiabilidade dos fatores extraídos pela AF por meio da consistência interna de cada item ou indicador foi realizado o teste alfa de Cronbach.

Seguindo a análise verificou-se que o tamanho da amostra e o número de itens são consistentes, o que sugere um bom grau de explicação dos dados $(\mathrm{KMO}=87.2 \%)$. A partir dos fatores encontrados na AF, verificou-se que os dados não são correlacionados (teste de Bartlett, p-valor < 0,001) viabilizando a utilização da AF. Os autovalores dos cinco fatores apresentaram-se maiores que um e o total da variância explicada foi de 57,57\%. Todas as comunalidades foram acima de 50\%, indicando uma boa relação dos itens com os fatores. A confiabilidade foi analisada considerando a consistência interna da escala, por meio do cálculo do Alpha de Cronbach, e os valores encontrados para o Alpha global foi de 0,894, o que mostra boa consistência interna do instrumento (Tabela 1).

Os fatores foram ordenados da seguinte forma: O fator 1, que representa "Maternidade", obteve os pesos mais elevados, pois o mesmo conseguiu explicar $27,19 \%$ do total da variância. O fator 2, que representa "Aborto", explicou $11,79 \%$ do total da variância. O fator 3, que representa "Prazer", atingiu 8,02\% do total da variância. O fator 4, que representa afetividade, conseguiu explicar 5,45\% do total da variância. O fator 5, que representa "Reprodução", explicou 5,12\% do total da variância.

Os itens dos fatores foram organizados em cinco dimensões: "Maternidade", que pretende avaliar a percepção da maternidade como projeto central do ser mulher; "Aborto", que avalia as representações negativas acerca do aborto; "Prazer", que avalia a percepção da sexualidade como área de prazer; “Afetividade”, que avalia em que medida a sexualidade é sentida como uma área de partilha de afetos; e "Reprodução", que avalia em que medida a sexualidade é entendida essencialmente como função procriativa.12 Para cotação dos dados, o referido instrumento foi respondido numa escala tipo Likert de cinco pontos, em que 1 = discordo totalmente; $2=$ discordo; $3=$ nem concordo nem discordo; $4=$ concordo; $5=$ concordo totalmente. 12

O score de cada dimensão é obtido a partir do somatório das pontuações de cada item. Quanto mais alta a pontuação nas dimensões consideradas, maiores seriam as crenças em: a maternidade ser projeto principal da condição feminina; a reprodução como função primordial da sexualidade feminina; a sexualidade como partilha de afeto; representações negativas sobre o aborto; e considerar o prazer como função primordial na sexualidade feminina (Sereno; Leal; Maroco, 2009).

As análises estatísticas foram realizadas no programa Statistical Package for the Social Sciences (SPSS) versão 20.0 e R/R Studio 2.15.3 (2013), por meio da seleção das variáveis de interesse. O nível de significância adotado para todos os testes foi de $5 \%$.

Para análise dos dados, inicialmente utilizou-se estatística descritiva, determinando as frequências absolutas e relativas, média e desvio-padrão. Posteriormente, na estatística analítica, executou-se a Análise de Variância com Múltiplos Fatores (ANOVA) juntamente com o teste de Tukey, para analisar se existiam ou não diferenças significativas entre as categorias das diversas variáveis independentes (socioeconômicas) e seus efeitos sobre a variável dependente (maternidade, aborto, prazer, afetividade e reprodução).

Por fim, executou-se a regressão linear simples de cada variável explicativa com o desfecho (cada dimensão do 
Instrumento QVCSMA) para ver o efeito bruto, em seguida, para construção do modelo múltiplo foram incluídas as variáveis com p-valor < 0,10; tendo como critério de ordem de entrada o menor p-valor. A seleção do modelo ajustado foi realizada a partir da avaliação da estatística F parcial e do coeficiente de determinação ajustado de cada modelo de regressão linear múltipla na medida em que as variáveis foram sendo incluídas, para isso utilizou-se intervalos de confiança de 95\% e nível de significância de $5 \%(\alpha=0,05)$.

O presente estudo atendeu as normas do Comitê de Ética em Pesquisa (CEP) da Universidade Federal do Espírito Santo, sendo aprovado em 25 de fevereiro de 2015, sob o parecer de número 971.389, respeitando todos os parâmetros éticos da Resolução 466/2012 da Comissão Nacional de Ética em Pesquisa (CONEP). Também foi autorizado pela Secretaria Estadual de Educação (SEDU), concedido pelo ofício de no 1223, de 17 de dezembro de 2014, carta de autorização do respectivo autor do instrumento.

\section{Resultados}

Dos 2.292 adolescentes de 15 a 19 anos entrevistados, 29,8\% (n=683) tinham 16 anos, 25,7\% (n=589) tinham 15 anos e $25,4 \%$ ( $n=582)$ tinham 17 anos. O sexo feminino correspondeu a 60,0\% $(n=1.376)$ da amostra. O primeiro ano do ensino médio abrangeu $47,7 \%(\mathrm{n}=1.094)$ dos entrevistados e o segundo ano $27,0 \%$ ( $\mathrm{n}=619)$. 
Tabela 2. Categorização dos itens do Instrumento Questionário de Valores e Crenças sobre Sexualidade Maternidade Aborto após analise fatorial. Região Metropolitana Da Grande Vitória, 2016-2017.

\begin{tabular}{|c|c|c|c|c|c|c|}
\hline Dimensões & $\begin{array}{c}\text { Discordo } \\
\text { totalmente } \\
\mathbf{N}(\%)\end{array}$ & $\begin{array}{l}\text { Discordo } \\
\mathbf{N}(\%)\end{array}$ & $\begin{array}{c}\text { Nem } \\
\text { concordo, } \\
\text { nem } \\
\text { discordo } \\
\mathbf{N}(\%)\end{array}$ & $\begin{array}{l}\text { Concordo } \\
\mathbf{N}(\%)\end{array}$ & $\begin{array}{c}\text { Concordo } \\
\text { totalmente } \\
\mathbf{N}(\%)\end{array}$ & $\begin{array}{l}\text { Total } \\
\mathbf{N}\end{array}$ \\
\hline \multicolumn{7}{|l|}{ PRAZER } \\
\hline $\begin{array}{l}\text { O sexo é a forma mais íntima de comunicação entre } \\
\text { duas pessoas }\end{array}$ & $150(6,5)$ & $227(9,9)$ & $487(21,2)$ & $743(32,4)$ & $582(25,4)$ & 2.189 \\
\hline $\begin{array}{l}\text { As relações sexuais são uma forma de demonstrar } \\
\text { carinho e afeto }\end{array}$ & $129(5,6)$ & $220(9,6)$ & $693(30,2)$ & $725(31,6)$ & $427(18,6)$ & 2.194 \\
\hline O sexo é uma parte muito importante da vida & $101(4,4)$ & $111(4,8)$ & $556(24,2)$ & $728(31,7)$ & $690(30,1)$ & 2.186 \\
\hline É importante ter prazer na relação sexual & $69(3,0)$ & $482,1)$ & $319(13,9)$ & $714(31,1)$ & $1039(45,3)$ & 2.189 \\
\hline Total & $449(5,1)$ & $606(6,9)$ & $2.055(23,5)$ & $2.910(33,2)$ & $2.738(31,3)$ & 8.758 \\
\hline \multicolumn{7}{|l|}{ AFETIVIDADE } \\
\hline As mulheres grávidas ficam bonitas & $191(8,3)$ & $233(10,2)$ & $825(36,0)$ & $620(27,0)$ & $310(13,5)$ & 2.179 \\
\hline $\begin{array}{l}\text { A minha principal motivação para as relações } \\
\text { sexuais é sentir-me amado(a) }\end{array}$ & $176(7,7)$ & $214(9,3)$ & $807(35,2)$ & $634(27,6)$ & $313(13,7)$ & 2.144 \\
\hline O sexo sem amor não faz sentido & $211(9,2)$ & $256(11,2)$ & $575(25,1)$ & $592(25,8)$ & $545(23,8)$ & 2.179 \\
\hline $\begin{array}{l}\text { As pessoas desejam ter filhos para os amarem e } \\
\text { serem amados por eles }\end{array}$ & $102(4,4)$ & $108(4,7)$ & $540(23,5)$ & $819(35,7)$ & $610(26,6)$ & 2.179 \\
\hline Total & $680(7,8)$ & $811(9,3)$ & $2.747(31,6)$ & $2.665(30,7)$ & $1.778(20,5)$ & 8.681 \\
\hline \multicolumn{7}{|l|}{ REPRODUÇÃO } \\
\hline Hoje em dia só engravida quem quer & $228(9,9)$ & $306(13,3)$ & $545(23,8)$ & $580(25,3)$ & $536(23,4)$ & 2.195 \\
\hline Fazer contracepção é fácil & $168(7,3)$ & $225(9,8)$ & $974(42,5)$ & $467(20,4)$ & $291(12,7)$ & 2.125 \\
\hline Existem vantagens e desvantagens em ter um filho & $87(3,8)$ & $137(6,0)$ & $651(28,4)$ & $866(37,8)$ & $454(19,8)$ & 2.195 \\
\hline Total & $483(7,4)$ & $668(10,2)$ & $2.170(33,3)$ & $1.913(29,4)$ & $1.281(19,7)$ & 6.515 \\
\hline \multicolumn{7}{|l|}{ MATERNIDADE } \\
\hline Todas as mulheres querem ser mães & $495(21,6)$ & $693(30,2)$ & $584(25,5)$ & $261(11,4)$ & $159(6,9)$ & 2.192 \\
\hline Engravidar é importante para as mulheres & $275(12,0)$ & $356(15,5)$ & $871(38,0)$ & $447(19,5)$ & $224(9,8)$ & 2.173 \\
\hline $\begin{array}{l}\text { A minha maior motivação para ter relações sexuais é } \\
\text { a reprodução }\end{array}$ & $619(27,0)$ & $599(26,1)$ & $635(27,7)$ & $192(8,4)$ & $104(4,5)$ & 2.149 \\
\hline Uma mulher é sempre responsável por uma gravidez & $545(23,8)$ & $526(22,9)$ & $595(25,9)$ & $338(14,7)$ & $178(7,8)$ & 2.182 \\
\hline Uma gravidez é sempre desejada & $616(26,9)$ & $697(30,4)$ & $596(26,0)$ & $185(8,1)$ & $93(4,1)$ & 2.187 \\
\hline Ter filhos é essencial para a realização da mulher & $350(15,3)$ & $336(14,7)$ & $755(32,9)$ & $454(19,8)$ & $295(12,9)$ & 2.190 \\
\hline A maternidade valoriza o status social da mulher & $326(14,2)$ & $355(15,5)$ & $860(37,5)$ & $420(18,3)$ & $218(9,5)$ & 2.179 \\
\hline Um casal sem filhos não é completamente feliz & $552(24,1)$ & $596(26,0)$ & $650(28,3)$ & $255(11,1)$ & $139(6,1)$ & 2.192 \\
\hline Ter um filho é necessário para a minha felicidade & $429(18,7)$ & $417(18,2)$ & $613(26,7)$ & $448(19,5)$ & $283(12,3)$ & 2.190 \\
\hline As mulheres que não desejam ter filhos são egoístas & $688(30,0)$ & $616(26,9)$ & $610(26,6)$ & $176(7,7)$ & $102(4,4)$ & 2.192 \\
\hline Total & $4.895(22,4)$ & $5.191(23,8)$ & $6.769(31,1)$ & $3.176(14,5)$ & $1.795(8,2)$ & 21.826 \\
\hline \multicolumn{7}{|l|}{ ABORTO } \\
\hline $\begin{array}{l}\text { O aborto pode ser prejudicial à saúde psicológica da } \\
\text { mulher }\end{array}$ & $37(1,6)$ & $212(9,2)$ & $527(23,0)$ & $776(33,8)$ & $614(26,8)$ & 2.167 \\
\hline $\begin{array}{l}\text { O aborto pode ser prejudicial à saúde física da } \\
\text { mulher }\end{array}$ & $111(4,8)$ & $106(4,6)$ & $369(16,1)$ & $730(31,8)$ & $868(37,9)$ & 2.184 \\
\hline O aborto é um crime em qualquer circunstância & $240(10,5)$ & $193(8,4)$ & $425(18,5)$ & $473(20,6)$ & $863(37,6)$ & 2.194 \\
\hline Total & $388(5,9)$ & $511(7,8)$ & $1.321(20,2)$ & $1.979(30,2)$ & $2.345(35,8)$ & 6.545 \\
\hline
\end{tabular}

Fonte: Autores.

A Tabela 2 expõe as maiores frequências e percentuais de cada item em cada dimensão do Instrumento QVCSMA após análise fatorial. Desse modo, 64,5\% dos adolescentes perceberam a sexualidade como área de prazer e função primordial da condição humana (64,5\%). Além disso, a sexualidade é sentida como uma área de partilha de afetos para $51,2 \%$ dos adolescentes e como função essencialmente procriativa para 49,1\%. Para a dimensão aborto, 66,0\% apresentaram percepções negativas sobre o mesmo, e 46,2\% discordam da percepção de maternidade como projeto principal da condição feminina. 
Tabela 3. Análise da variância das dimensões das diferentes funções da sexualidade, maternidade e aborto do instrumento QVCSMA com os fatores socioeconômicos (comparação das médias).

\begin{tabular}{|c|c|c|c|c|c|c|c|c|c|c|c|}
\hline \multirow{2}{*}{$\begin{array}{c}\text { DIMENSÕES } \\
\text { Fatores Socioeconômicos }\end{array}$} & \multirow[b]{2}{*}{$\mathrm{N}^{\$}$} & \multicolumn{2}{|c|}{ Prazer } & \multicolumn{2}{|c|}{ Afetividade } & \multicolumn{2}{|c|}{ Reprodução } & \multicolumn{2}{|c|}{ Maternidade } & \multicolumn{2}{|c|}{ Aborto } \\
\hline & & Média* & $\mathrm{DP}$ & Média* & DP & Média* & $\mathrm{DP}$ & Média* & $\mathrm{DP}$ & Média* & DP \\
\hline Idade & & & & & & & & & & & \\
\hline Quinze/Dezesseis & 1232 & $2,74^{\mathrm{a}}$ & 0,81 & 2,45 & 0,80 & 2,43 & 0,82 & $1,59^{\mathrm{a}}$ & 0,82 & 2,82 & 1,03 \\
\hline Dezessete & 548 & $2,84^{\mathrm{a}}$ & 0,83 & 2,47 & 0,86 & 2,41 & 0,86 & $1,61^{\mathrm{b}}$ & 0,82 & 2,86 & 1,03 \\
\hline Dezoito/Dezenove & 414 & 2,82 & 0,78 & 2,53 & 0,84 & 2,49 & 0,81 & $1,76^{\mathrm{a}, \mathrm{b}}$ & 0,84 & 2,79 & 0,97 \\
\hline Total & & 2,78 & 0,81 & 2,47 & 0,82 & 2,44 & 0,83 & 1,63 & 0,83 & 2,83 & 1,02 \\
\hline \multicolumn{12}{|l|}{ Sexo } \\
\hline Feminino & 1331 & 2,73 & 0,80 & 2,57 & 0,80 & 2,45 & 0,83 & 1,58 & 0,85 & 2,88 & 1,00 \\
\hline Masculino & 865 & 2,87 & 0,82 & 2,32 & 0,82 & 2,41 & 0,84 & 1,70 & 0,79 & 2,74 & 1,04 \\
\hline Total & & 2,78 & 0,81 & 2,47 & 0,82 & 2,44 & 0,83 & 1,63 & 0,83 & 2,83 & 1,02 \\
\hline \multicolumn{12}{|l|}{ Ano do Ensino Médio } \\
\hline Primeiro ano & 1040 & $2,73^{\mathrm{a}}$ & 0,84 & 2,45 & 0,83 & $2,38^{\mathrm{a}}$ & 0,85 & $1,68^{\mathrm{a}, \mathrm{b}}$ & 0,84 & 2,83 & 1,02 \\
\hline Segundo ano & 607 & 2,81 & 0,76 & 2,51 & 0,79 & $2,50^{\mathrm{a}}$ & 0,80 & $1,57^{\mathrm{a}}$ & 0,83 & 2,85 & 1,03 \\
\hline Terceiro ano & 550 & $2,85^{\mathrm{a}}$ & 0,78 & 2,47 & 0,83 & 2,48 & 0,82 & $1,58^{\mathrm{b}}$ & 0,79 & 2,79 & 1,01 \\
\hline Total & & 2,78 & 0,81 & 2,47 & 0,82 & 2,44 & 0,83 & 1,63 & 0,83 & 2,83 & 1,02 \\
\hline \multicolumn{12}{|l|}{ Situação Conjugal } \\
\hline Vive com companheiro (a) & 140 & 2,78 & 0,89 & 2,65 & $0,87^{\mathrm{a}}$ & 2,39 & 0,89 & $2,11^{\mathrm{a}, \mathrm{b}}$ & 0,82 & 2,85 & 1,04 \\
\hline Tem companheiro (a), mas não vive com ele & 480 & $2,91^{\mathrm{a}}$ & 0,74 & 2,60 & $0,77^{\mathrm{b}}$ & $2,56^{\mathrm{a}}$ & 0,79 & $1,66^{\mathrm{a}}$ & 0,84 & 2,87 & 1,01 \\
\hline Não tem companheiro (a) & 1556 & $2,74^{\mathrm{a}}$ & 0,82 & 2,42 & $0,83^{\mathrm{a}, \mathrm{b}}$ & $2,41^{\mathrm{a}}$ & 0,84 & $1,57^{\mathrm{b}}$ & 0,81 & 2,81 & 1,02 \\
\hline Total & & 2,78 & 0,81 & 2,47 & 0,82 & 2,44 & 0,83 & 1,62 & 0,83 & 2,83 & 1,02 \\
\hline \multicolumn{12}{|l|}{ Raça/Cor } \\
\hline Preta & 388 & 2,78 & 0,76 & 2,48 & 0,85 & 2,45 & 0,82 & $1,71^{\mathrm{a}}$ & 0,80 & 2,83 & 1,03 \\
\hline Parda (morena/mulata) & 993 & $2,74^{\mathrm{a}}$ & 0,86 & 2,45 & 0,84 & 2,42 & 0,86 & $1,65^{\mathrm{b}}$ & 0,83 & $2,90^{\mathrm{a}}$ & 0,97 \\
\hline Branca & 625 & $2,85^{\mathrm{a}}$ & 0,75 & 2,48 & 0,78 & 2,44 & 0,80 & $1,54^{\mathrm{a}, \mathrm{b}}$ & 0,83 & $2,70^{\mathrm{a}}$ & 1,07 \\
\hline Total & & 2,78 & 0,81 & 2,47 & 0,82 & 2,43 & 0,83 & 1,62 & 0,83 & 2,82 & 1,02 \\
\hline \multicolumn{12}{|l|}{ Trabalho Remunerado } \\
\hline Não & 1682 & 2,77 & 0,81 & 2,47 & 0,82 & 2,45 & 0,83 & 1,60 & 0,83 & 2,81 & 1,02 \\
\hline Sim & 513 & 2,83 & 0,80 & 2,46 & 0,83 & 2,40 & 0,84 & 1,72 & 0,81 & 2,88 & 1,00 \\
\hline Total & & 2,78 & 0,81 & 2,47 & 0,82 & 2,437 & 0,83 & 1,63 & 0,83 & 2,83 & 1,02 \\
\hline \multicolumn{12}{|l|}{ Chefe da Família } \\
\hline Pai & 1100 & 2,80 & 0,79 & 2,47 & 0,80 & 2,45 & 0,82 & 1,64 & 0,82 & 2,82 & 1,02 \\
\hline Mãe & 850 & $2,72^{\mathrm{a}}$ & 0,83 & 2,46 & 0,84 & 2,42 & 0,84 & 1,60 & 0,83 & 2,80 & 1,01 \\
\hline Outros & 239 & $2,89^{\mathrm{a}}$ & 0,81 & 2,49 & 0,87 & 2,42 & 0,87 & 1,65 & 0,84 & 2,96 & 1,02 \\
\hline Total & & 2,78 & 0,81 & 2,47 & 0,82 & 2,44 & 0,83 & 1,63 & 0,83 & 2,83 & 1,02 \\
\hline \multicolumn{12}{|l|}{ Grau de Instrução do Chefe da Família } \\
\hline Analfabeto/Fund. I incompleto & 144 & $2,62^{\mathrm{a}}$ & 0,89 & 2,50 & 0,82 & 2,49 & 0,77 & $1,83^{\mathrm{a}, \mathrm{b}}$ & 0,71 & $2,98^{\mathrm{a}}$ & 0,86 \\
\hline Fund. I completo & 371 & 2,74 & 0,84 & 2,47 & 0,87 & $2,54^{\mathrm{a}}$ & 0,86 & $1,72^{\mathrm{c}, \mathrm{d}}$ & 0,84 & $2,94^{\mathrm{b}}$ & 0,95 \\
\hline Fund. II completo & 497 & 2,82 & 0,79 & 2,51 & 0,76 & $2,49^{b}$ & 0,78 & $1,77^{\mathrm{e}, \mathrm{f}}$ & 0,81 & $2,92^{\mathrm{c}}$ & 1,01 \\
\hline Médio completo & 735 & 2,79 & 0,78 & 2,49 & 0,81 & $2,43^{\mathrm{c}}$ & 0,85 & $1,54^{\mathrm{a}, \mathrm{c}, \mathrm{e}}$ & 0,82 & 2,78 & 1,04 \\
\hline Superior completo & 404 & $2,85^{\mathrm{a}}$ & 0,81 & 2,39 & 0,86 & $2,28^{\mathrm{a}, \mathrm{b}, \mathrm{c}}$ & 0,82 & $1,46^{\mathrm{b}, \mathrm{d}, \mathrm{f}}$ & 0,84 & $2,62^{a, b, c}$ & 1,09 \\
\hline Total & & 2,79 & 0,81 & 2,47 & 0,82 & 2,44 & 0,83 & 1,63 & 0,83 & 2,82 & 1,02 \\
\hline \multicolumn{12}{|l|}{ Renda Total da Família } \\
\hline$\leq 1$ salário mínimo & 290 & $2,57^{\mathrm{a}, \mathrm{b}}$ & 0,92 & 2,40 & 0,91 & 2,39 & 0,86 & $1,80^{\mathrm{a}}$ & 0,83 & 2,81 & 1,00 \\
\hline 1 a 3 salários mínimos & 760 & $2,79^{\mathrm{a}, \mathrm{c}}$ & 0,80 & 2,53 & 0,82 & 2,48 & 0,84 & $1,70^{\mathrm{b}}$ & 0,81 & $2,94^{\mathrm{a}}$ & 0,99 \\
\hline > 3 salários mínimos & 748 & $2,88^{\mathrm{b}, \mathrm{c}}$ & 0,79 & 2,43 & 0,82 & 2,46 & 0,84 & $1,51^{\mathrm{a}, \mathrm{b}}$ & 0,83 & $2,70^{\mathrm{a}}$ & 1,05 \\
\hline Total & & 2,79 & 0,82 & 2,47 & 0,84 & 2,45 & 0,84 & 1,64 & 0,83 & 2,82 & 1,02 \\
\hline \multicolumn{12}{|l|}{ Pais Divorciados/Separados } \\
\hline Não & 1281 & 2,77 & 0,83 & 2,47 & 0,82 & 2,44 & 0,82 & 1,65 & 0,83 & 2,83 & 1,00 \\
\hline Sim & 895 & 2,80 & 0,78 & 2,46 & 0,83 & 2,44 & 0,85 & 1,60 & 0,82 & 2,81 & 1,04 \\
\hline Total & & 2,78 & 0,81 & 2,47 & 0,82 & 2,44 & 0,83 & 1,63 & 0,83 & 2,83 & 1,02 \\
\hline
\end{tabular}

$\$ \mathrm{Na}$ coluna do total $(\mathrm{N})$, registrou-se o total da categoria com maior número de dados faltantes dentre as dimensões.

* Após execução do Teste ANOVA, foi executado o Teste de Tukey para p-valores significantes no primeiro teste. As letras a,b,c mostram diferenças de médias significantes ( $\mathrm{p}$-valor $<5 \%$ ) para as categorias com letras iguais. Fonte: Autores. 
A Tabela 3 apresenta a análise da variância (ANOVA) por variável de cada dimensão e as diferenças de médias (DM) entre as categorias de cada variável (teste de Tukey). Para a variável idade houve diferença de médias significativa nas dimensões prazer e maternidade. A variável sexo, apresentou DM significativa na dimensão prazer, afetividade, maternidade e aborto. A variável ano do ensino médio, as DM apresentaram-se nas dimensões prazer, reprodução e maternidade.

$\mathrm{Na}$ variável situação conjugal, houve DM significativa para as dimensões prazer, afetividade, reprodução e maternidade. Quanto à raça/cor, as DM significativas foram para as dimensões prazer, maternidade e aborto. Na variável trabalho remunerado há DM somente na dimensão maternidade. Já para a variável, chefe da família, somente para dimensão prazer.

Em relação à variável grau de instrução do chefe da família, as DM apresentam-se nas dimensões prazer, reprodução, maternidade e aborto. Por fim, a variável renda total da família, que as DM foram significativas para as dimensões prazer, afetividade $(\mathrm{p}=0,031)$ entre os grupos, porém em subconjuntos não apresentou diferença significativa, maternidade e aborto. O fato de ter pais divorciados ou separados não influenciou nas análises.

Tabela 4. Regressão linear simples de cada variável explicativa com cada dimensão do QVCSMA (desfecho) em estudantes de 15 a 19 anos, RMGV/ES.

\begin{tabular}{|c|c|c|c|c|c|}
\hline Dimensões & Fatores Socioeconômicos & $\beta$ & $\mathbf{t}$ & P-valor & $\mathbf{R}^{2}$ \\
\hline & Idade $15 / 16$ anos (referência)* & & & & \\
\hline & Idade 17 anos & 0,099 & 2,417 & 0,015 & \multirow{2}{*}{0,002} \\
\hline & Idade $18 / 19$ anos & 0,078 & 1,719 & 0,085 & \\
\hline & Sexo feminino (referência)* & & & & \multirow{3}{*}{0,007} \\
\hline & Sexo masculino & 0,142 & 4,069 & $<0,001$ & \\
\hline & $1^{\circ}$ ano do ensino médio (referência)* & & & & \\
\hline & $2^{\circ}$ ano do ensino médio & 0,084 & 2,055 & 0,040 & \multirow{2}{*}{0,004} \\
\hline & $3^{\circ}$ ano do ensino médio & 0,116 & 2,738 & 0,006 & \\
\hline & Vive com companheiro (referência)* & & & & \\
\hline & Tem companheiro, mas não vive com ele & 0,125 & 1,624 & 0,104 & 0006 \\
\hline & Não tem companheiro & $-0,039$ & $-0,554$ & 0,579 & 0,000 \\
\hline & raça/cor branca (referência)* & & & & \\
\hline & Raça/cor preta & $-0,074$ & $-1,438$ & 0,150 & 0 \\
\hline & Raça/cor parda & $-0,112$ & $-2,731$ & 0,006 & \\
\hline \multirow[t]{14}{*}{ PRAZER } & Sem trabalho remunerado (referência)* & & & & \\
\hline & Com trabalho remunerado & 0,058 & 1,434 & 0,152 & 0,001 \\
\hline & Pai como chefe da família (referência)* & & & & \\
\hline & Mãe como chefe da família & $-0,079$ & $-2,177$ & $\mathbf{0 , 0 2 9}$ & \multirow{2}{*}{0,003} \\
\hline & Outros como chefe da família & 0,080 & 1,416 & 0,156 & \\
\hline & Chefe da família analfabeto (referência)* & & & & \\
\hline & Chefe da família fundamental incompleto & 0,122 & 1,552 & 0,120 & \multirow{4}{*}{0,004} \\
\hline & Chefe da família fundamental completo & 0,204 & 2,695 & $\mathbf{0 , 0 0 7}$ & \\
\hline & Chefe da família ensino médio & 0,173 & 2,369 & $\mathbf{0 , 0 1 7}$ & \\
\hline & Chefe da família ensino superior & 0,237 & 3,056 & 0,002 & \\
\hline & Renda total da família $<1$ salário (referência)* & & & & \multirow{4}{*}{0,015} \\
\hline & Renda total da família entre 1 e 3 salários & 0,227 & 4,070 & $<0,001$ & \\
\hline & Renda total da família $>3$ salários & 0,311 & 5,549 & $<0,001$ & \\
\hline & Pais com união estável (referência)* & & & & \\
\hline
\end{tabular}




\begin{tabular}{|c|c|c|c|c|c|}
\hline & Pais separados/divorciados & 0,023 & 0,653 & 0,514 & 0,000 \\
\hline \multirow{19}{*}{ AFETIVIDADE } & Idade 17 anos & 0,017 & 0,420 & 0,674 & \multirow{2}{*}{0,000} \\
\hline & Idade $18 / 19$ anos & 0,074 & 1,592 & 0,111 & \\
\hline & Sexo masculino & $-0,256$ & $-7,238$ & $<0,001$ & 0,023 \\
\hline & $2^{\circ}$ ano do ensino médio & 0,061 & 1,479 & 0,139 & \multirow{2}{*}{0,000} \\
\hline & $3^{\circ}$ ano do ensino médio & 0,026 & 0,602 & 0,547 & \\
\hline & Tem companheiro, mas não vivi com ele & $-0,046$ & $-0,594$ & 0,552 & \multirow{2}{*}{0,011} \\
\hline & Não tem companheiro & $-0,230$ & $-3,210$ & $\mathbf{0 , 0 0 1}$ & \\
\hline & Raça/cor preta & 0,002 & 0,053 & 0,957 & \multirow{2}{*}{0,000} \\
\hline & Raça/cor parda & $-0,024$ & $-0,575$ & 0,565 & \\
\hline & Trabalho remunerado sim & $-0,016$ & $-0,393$ & 0,694 & 0,000 \\
\hline & Chefe da família mãe & $-0,013$ & $-0,337$ & 0,736 & \multirow{2}{*}{0,000} \\
\hline & Chefe da família outros & 0,018 & 0,315 & 0,753 & \\
\hline & Chefe da família fundamental incompleto & $-0,031$ & $-0,392$ & 0,695 & \multirow{4}{*}{0,000} \\
\hline & Chefe da família fundamental completo & 0,013 & 0,176 & 0,860 & \\
\hline & Chefe da família ensino médio & $-0,012$ & $-0,167$ & 0,868 & \\
\hline & Chefe da família ensino superior & $-0,105$ & $-1,327$ & 0,185 & \\
\hline & Renda total da família entre 1 e 3 salários & 0,125 & 2,185 & $\mathbf{0 , 0 2 9}$ & \multirow{2}{*}{0,002} \\
\hline & Renda total da família $>3$ salários & 0,031 & 0,549 & 0,583 & \\
\hline & Pais separados/divorciados & $-0,011$ & $-0,317$ & 0,751 & 0,000 \\
\hline \multirow{19}{*}{ REPRODUCAO } & Idade 17 anos & $-0,019$ & $-0,452$ & 0,652 & \multirow{2}{*}{0,000} \\
\hline & Idade $18 / 19$ anos & 0,059 & 1,265 & 0,206 & \\
\hline & Sexo masculino & $-0,041$ & $-1,144$ & 0,253 & 0,000 \\
\hline & $2^{\circ}$ ano do ensino médio & 0,120 & 2,857 & 0,004 & \multirow{2}{*}{0,003} \\
\hline & $3^{\circ}$ ano do ensino médio & 0,097 & 2,227 & $\mathbf{0 , 0 2 6}$ & \\
\hline & Tem companheiro, mas não vivi com ele & 0,178 & 2,243 & $\mathbf{0 , 0 2 5}$ & \multirow{2}{*}{0,005} \\
\hline & Não tem companheiro & 0,021 & 0,288 & 0,773 & \\
\hline & Raça/cor preta & $-0,014$ & $-0,264$ & 0,792 & \multirow{2}{*}{0,000} \\
\hline & Raça/cor parda & $-0,018$ & $-0,441$ & 0,660 & \\
\hline & Trabalho remunerado sim & $-0,052$ & $-1,265$ & 0,206 & 0,000 \\
\hline & Chefe da família mãe & $-0,031$ & $-0,835$ & 0,404 & \multirow{2}{*}{0,000} \\
\hline & Chefe da família outros & $-0,033$ & $-0,563$ & 0,574 & \\
\hline & Chefe da família fundamental incompleto & 0,048 & 0,602 & 0,547 & \multirow{4}{*}{0,008} \\
\hline & Chefe da família fundamental completo & 0,001 & 0,025 & 0,980 & \\
\hline & Chefe da família ensino médio & $-0,058$ & $-0,771$ & 0,440 & \\
\hline & Chefe da família ensino superior & $-0,209$ & $-2,615$ & $\mathbf{0 , 0 0 8}$ & \\
\hline & Renda total da família entre 1 e 3 salários & 0,087 & 1,502 & 0,133 & \multirow{2}{*}{0,000} \\
\hline & Renda total da família $>3$ salários & 0,070 & 1,207 & 0,228 & \\
\hline & Pais separados/divorciados & 0,002 & 0,072 & 0,943 & 0,000 \\
\hline \multirow{7}{*}{ MATERNIDADE } & Idade 17 anos & 0,024 & 0,584 & 0,559 & \multirow{2}{*}{0,005} \\
\hline & Idade $18 / 19$ anos & 0,174 & 3,766 & $<0,001$ & \\
\hline & Sexo masculino & 0,126 & 3,535 & $<0,001$ & 0,005 \\
\hline & $2^{\circ}$ ano do ensino médio & $-0,114$ & $-2,739$ & 0,006 & \multirow{2}{*}{0,004} \\
\hline & $3^{\circ}$ ano do ensino médio & $-0,103$ & $-2,391$ & $\mathbf{0 , 0 1 6}$ & \\
\hline & Tem companheiro, mas não vivi com ele & $-0,453$ & $-5,804$ & $<0,001$ & \multirow{2}{*}{0,025} \\
\hline & Não tem companheiro & $-0,539$ & $-7,517$ & $<0,001$ & \\
\hline
\end{tabular}




\begin{tabular}{|c|c|c|c|c|c|}
\hline & Raça/cor preta & 0,175 & 3,312 & $<0,001$ & \multirow{2}{*}{0,005} \\
\hline & Raça/cor parda & 0,108 & 2,587 & 0,009 & \\
\hline & Trabalho remunerado sim & 0,118 & 2,876 & $\mathbf{0 , 0 0 4}$ & 0,003 \\
\hline & Chefe da família mãe & $-0,041$ & $-1,097$ & 0,273 & \multirow{2}{*}{0,000} \\
\hline & Chefe da família outros & 0,012 & 0,218 & 0,827 & \\
\hline & Chefe da família fundamental incompleto & $-0,111$ & $-1,399$ & 0,162 & \multirow{4}{*}{0,023} \\
\hline & Chefe da família fundamental completo & $-0,054$ & $-0,710$ & 0,478 & \\
\hline & Chefe da família ensino médio & $-0,289$ & $-3,904$ & $<0,001$ & \\
\hline & Chefe da família ensino superior & $-0,364$ & $-4,627$ & $<0,001$ & \\
\hline & Renda total da família entre 1 e 3 salários & $-0,095$ & $-1,689$ & 0,092 & \multirow{2}{*}{0,017} \\
\hline & Renda total da família $>3$ salários & $-0,286$ & $-5,038$ & $<0,001$ & \\
\hline & Pais separados/divorciados & $-0,051$ & $-1,447$ & 0,148 & 0,000 \\
\hline \multirow{19}{*}{ ABORTO } & Idade 17 anos & 0,041 & 0,791 & 0,429 & \multirow[t]{2}{*}{0,000} \\
\hline & Idade $18 / 19$ anos & $-0,028$ & $-0,497$ & 0,619 & \\
\hline & Sexo masculino & $-0,143$ & $-3,230$ & $\mathbf{0 , 0 0 1}$ & 0,004 \\
\hline & $2^{\circ}$ ano do ensino médio & 0,025 & 0,491 & 0,624 & \multirow[t]{2}{*}{0,000} \\
\hline & $3^{\circ}$ ano do ensino médio & $-0,036$ & $-0,686$ & 0,493 & \\
\hline & Tem companheiro, mas não vivi com ele & 0,021 & 0,219 & 0,827 & \multirow[t]{2}{*}{0,000} \\
\hline & Não tem companheiro & $-0,033$ & $-0,368$ & 0,713 & \\
\hline & Raça/cor preta & 0,132 & 2,020 & $\mathbf{0 , 0 4 3}$ & \multirow[t]{2}{*}{0,006} \\
\hline & Raça/cor parda & 0,206 & 3,972 & $<0,001$ & \\
\hline & Trabalho remunerado sim & 0,073 & 1,434 & 0,152 & 0,000 \\
\hline & Chefe da família mãe & $-0,016$ & $-0,355$ & 0,722 & \multirow[t]{2}{*}{0,001} \\
\hline & Chefe da família outros & 0,137 & 1,896 & $\mathbf{0 , 0 5 8}$ & \\
\hline & Chefe da família fundamental incompleto & $-0,036$ & $-0,371$ & 0,710 & \multirow[t]{4}{*}{0,012} \\
\hline & Chefe da família fundamental completo & $-0,056$ & $-0,589$ & 0,556 & \\
\hline & Chefe da família ensino médio & $-0,203$ & $-2,204$ & $\mathbf{0 , 0 2 7}$ & \\
\hline & Chefe da família ensino superior & $-0,362$ & $-3,681$ & $<0,001$ & \\
\hline & Renda total da família entre 1 e 3 salários & 0,133 & 1,904 & $\mathbf{0 , 0 5 7}$ & \multirow[t]{2}{*}{0,011} \\
\hline & Renda total da família >3 salários & $-0,109$ & $-1,549$ & 0,121 & \\
\hline & Pais separados/divorciados & $-0,021$ & $-0,477$ & 0,633 & 0,000 \\
\hline
\end{tabular}

*As categorias de referência foram descritas na primeira dimensão (PRAZER) e omitidas nas dimensões subsequentes, na seguinte ordem: idade 15/16 anos; sexo feminino; $1^{\circ}$ ano do ensino médio; vive com companheiro; raça/cor preta; trabalho remunerado não; chefe da família pai; chefe da família analfabeto; renda total da família <1 salário e pais com união estável.

Fonte: Autores.

A Tabela 4 apresenta a regressão linear simples para verificar a associação entre as variáveis dependentes (QVCSMA) e independentes (fatores socioeconômicos) e o quanto cada variável independente influencia na média de resposta em cada dimensão isoladamente. Apenas as variáveis com $\mathrm{p}$-valor $\leq 0,10$ (em negrito) foram levadas em consideração na análise múltipla.

Na análise múltipla (Tabela 5), permaneceu no modelo da dimensão prazer: ser do sexo masculino, que aumenta a média em 0,119 da escala Likert; ser do terceiro ano do ensino médio aumenta a média em 0,103; renda familiar entre 1 e 3 salários aumenta à média em 0,213; e maior que 3 salários aumenta a média em 0,286, ao levar em consideração todas as variáveis incluídas no modelo. Para a dimensão afetividade, ser do sexo masculino diminui o valor da média em -0,231 da escala Likert, não ter companheiro diminui a média em -0,209 e renda familiar entre 1 e 3 salários aumenta a média em 0,153. 
Quanto à dimensão reprodução, ser do segundo ano do ensino médio aumentou a média da escala Likert em 0,107, o chefe da família ter o ensino superior diminuiu em -0,208 e ter companheiro, mas não viver com ele aumentou a média em 0,164.

A dimensão maternidade foi a que mais apresentou variáveis associadas: idade de 18/19 anos, aumentou a média 0,154; ser do sexo masculino aumenta em 0,161 ; ser do segundo ou terceiro ano diminuiu a média (-0,118 e -0,172, respectivamente), assim como ter companheiro, mas não viver com ele e não ter companheiro (-0,341 e $-0,441$, respectivamente); possuir um trabalho remunerado aumenta 0,113 , o chefe da família ter ensino médio ou superior diminui a média (-0,234 e -0,246, respectivamente) e a renda familiar maior que três salários diminui a média em -0,234 da escala Likert. E a dimensão aborto tem a sua média diminuída pela variável chefe da família com ensino superior $(-0,300)$ e aumentada pelas variáveis raça/cor parda $(0,133)$ e renda familiar entre 1 e 3 salários $(0,149)$.

Tabela 5. Fatores socioeconômicos associados as dimensões do QVCSMA em estudantes de 15 a 19 anos, segundo análise de regressão linear múltipla, RMGV/ES.

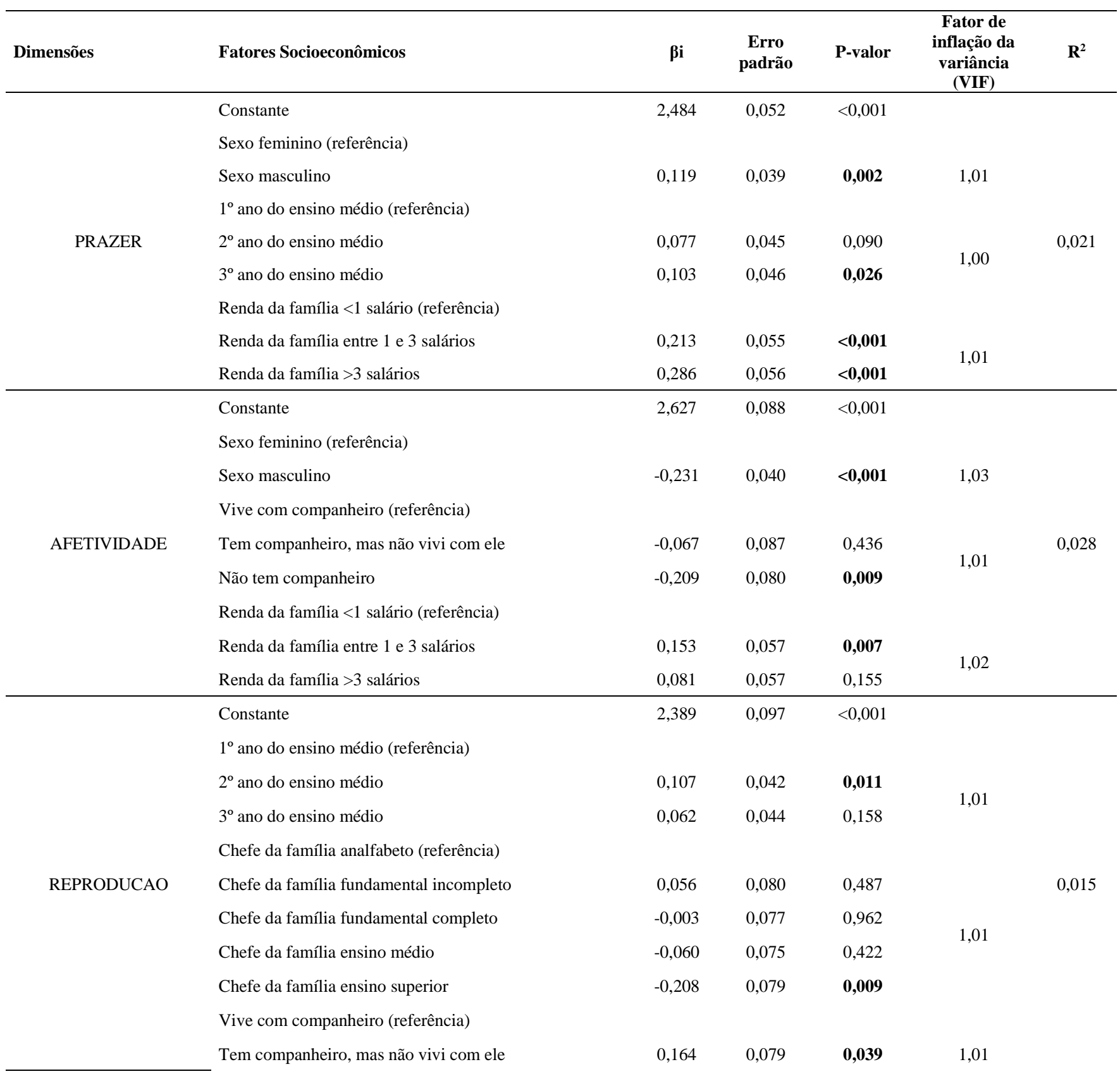


Research, Society and Development, v. 10, n. 13, e572101321494, 2021

(CC BY 4.0) | ISSN 2525-3409 | DOI: http://dx.doi.org/10.33448/rsd-v10i13.21494

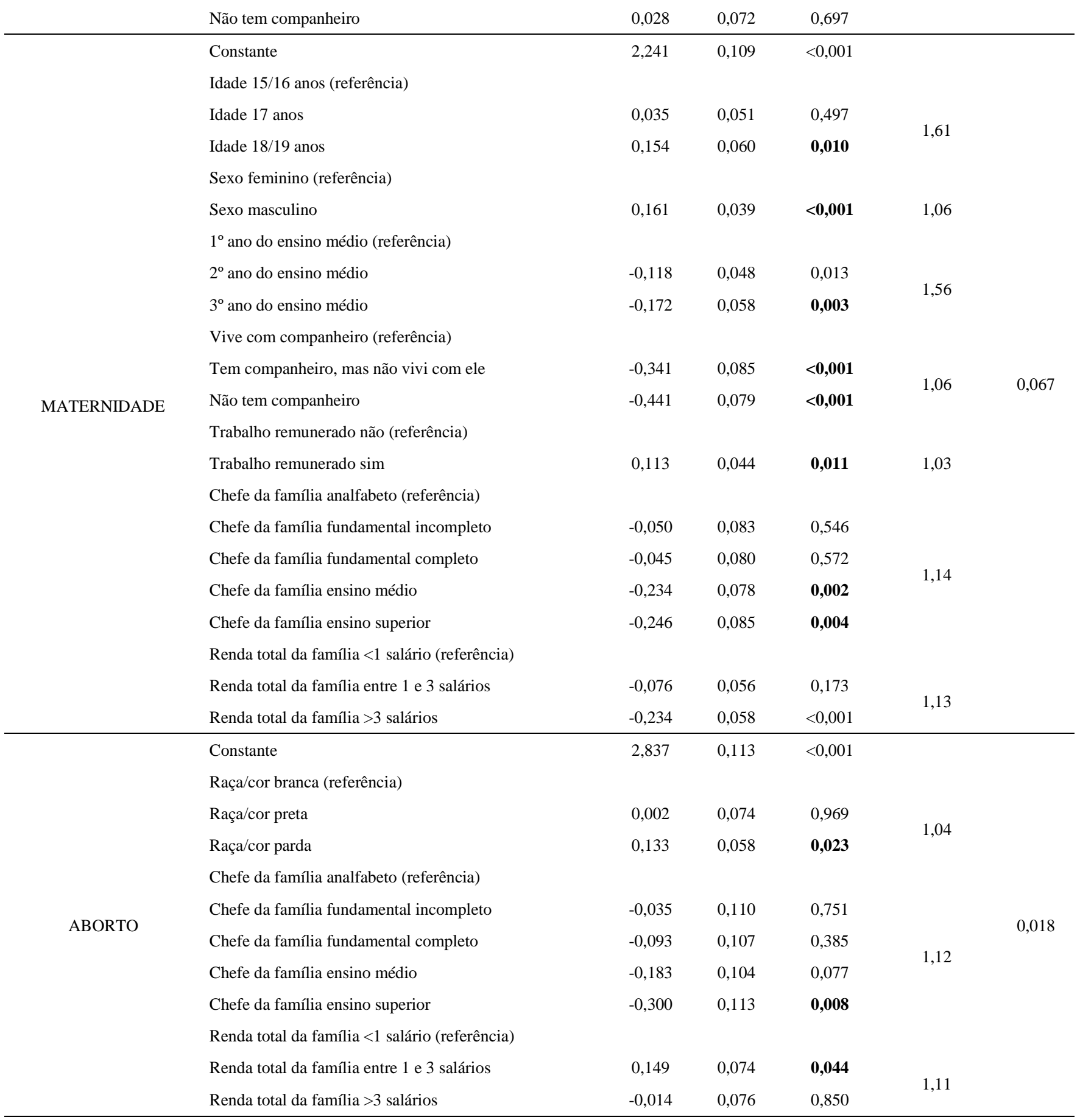

Fonte: Autores.

A Tabela 5 também mostra a avaliação da multicolinearidade entre as variáveis explicativas do modelo final, a fim de verificar se alguma variável explicativa estava correlacionada com outra, o que poderia enviesar a análise. Considerando que nenhum valor de fator de inflação da variância (VIF) foi maior que 10, pode-se afirmar que não havia colinearidade entre as variáveis explicativas do modelo.

\section{Discussão}

A percepção de sexualidade, maternidade e aborto é influenciada por variáveis socioeconômicas, caracterizando em maior ou menor grau os riscos à saúde sexual e reprodutiva, conforme a vivência de cada indivíduo. As vulnerabilidades 
ampliam-se, considerando que a adolescência é um período de mudanças, vinculada ao aprendizado das moralidades sociais, dos valores, da sociabilidade, dos modelos de gênero e das experiências dificultosas (Aquino et al., 2003).

As diferenças nas percepções devem ser consideradas na medida em que a liberdade de vivência da sexualidade é um comportamento recente na sociedade para as meninas, visto que essa liberdade era comportamento exclusivo masculino até metade do século passado. Essa mudança foi legitimada na década de 1960/1970 no Brasil, com o movimento feminista e o advento da pílula anticoncepcional, que permitiram ressignificar o lugar do homem e da mulher na sociedade, passando a exercer o direito de escolha para a maternidade (Arán, 2003).

Tais mudanças também provocaram uma atenção especial à saúde sexual e reprodutiva do adolescente, principalmente a saúde reprodutiva, visto que a adolescência deixa de ser o período apropriado para a reprodução, havendo uma imposição da sociedade para a qualificação profissional (Heilborn et al., 2006).

Neste estudo, a percepção positiva dos adolescentes em relação à sexualidade como área de "prazer" evidencia liberdade na vivência da sexualidade e está vinculada ao empoderamento social e educacional de cada indivíduo (Carvalho et al., 2016). Essa percepção é influenciada diretamente por condições socioeconômicas favoráveis ao desenvolvimento do adolescente, visto que, os adolescentes com maior grau de instrução, podem vivenciar um relacionamento amoroso de namoro e possuir maior renda familiar representam os indivíduos que conseguem exercer a sexualidade minimizando os riscos.

Esses achados corroboram com estudos (Carvalho et al., 2016; Ahorlu, Pfeiffer \& Obrist, 2015), que observaram a presença de condições socioeconômicas desfavoráveis como fator associado à maior risco para saúde sexual do adolescente. E ser do sexo masculino já pressupõe uma vivência da sexualidade vantajosa socioculturalmente em relação ao sexo feminino, devido a influência psicossocial que percorreu durante a história das civilizações antigas que deram origem as concepções sobre a sexualidade humana ocidental (Arán, 2003).

Entretanto, a percepção positiva do adolescente em relação à sexualidade quanto à "afetividade", pode ser característica da idade, visto que a imaturidade e a instabilidade emocional da adolescência (Beserra et al., 2017) aumentam as chances de exposição aos riscos para a saúde sexual e reprodutiva (Silva et al., 2015). Essas percepções são também características de adolescentes em contexto de maior vulnerabilidade econômica e social, devido à falta de oportunidades de ascensão social, associada às vulnerabilidades individuais (Nery et al., 2015). No presente estudo, observa-se que as maiores médias se encontram associados a fatores socioeconômicos desfavoráveis ao desenvolvimento do adolescente, porém as variáveis que realmente interferem na percepção para essa dimensão, são: ser do sexo masculino, não ter companheiro e viver com uma renda familiar entre 1 e 3 salários mínimos. Segundo dados da UNICEF (2015), para as meninas, a convivência com companheiro já na infância e adolescência afeta diretamente sua saúde e os seus direitos sexuais e reprodutivos, além disso, pode estar relacionada à maior exposição à violência doméstica ou mesmo à coerção pelo parceiro, sendo em maior proporção se o parceiro for mais velho.

A percepção dos adolescentes quanto à sexualidade como função de "reprodução" foi predominante, evidenciando fragilidade da capacidade do adolescente em desfrutar uma vivência sexual satisfatória, uma vez que essa percepção (Sereno; Leal \& Maroco, 2013), é característica de indivíduos sexualmente ativos que não fazem uso de preservativo e/ou contraceptivo, e de condição socioeconômica mais baixa. Neste estudo, verifica-se que para essa percepção não apresentou extremos de fatores socioeconômicos favoráveis ou desfavoráveis, porém fatores que interferiram significativamente foram os relacionados ao grau de conhecimento tanto do adolescente quanto dos responsáveis parentais (estar cursando o segundo ano do ensino médio e o grau de instrução do chefe da família ser fundamental I completo/fundamental II incompleto), o que pode ainda estar relacionado à dificuldade de acesso a conversas sobre sexualidade com os responsáveis parentais. Fundamentalmente, os pais podem ter um importante papel como principais educadores de seus filhos, influenciando diretamente o comportamento sexual. No entanto, a falta de conhecimento, de habilidades ou desconforto ao falar de 
sexualidade, pode impedi-los do cumprimento bem-sucedido desse papel (Breuner \& Mattson, 2016). Esse fato é preocupante, por ser a educação sexual, em parte, dependente do nível educacional familiar (Sousa \& Gomes, 2009).

A vinculação da sexualidade à reprodução representa um retrocesso (Arán, 2003), visto que em pleno século XXI, com a legitimação da pílula contraceptiva há mais de 40 anos e a ampla e sistemática distribuição de preservativos masculinos há mais de 20 anos pelo Sistema Único de Saúde (SUS) (Brasil, 2006), ainda existe resistência ao seu uso. O não uso de preservativo na primeira relação sexual é preocupante para a saúde sexual dos adolescentes, pois além de um método preventivo é também educativo, pois gera comportamento saudável que se reflete por toda a vida do indivíduo (Silva et al., 2015).

Quanto à "maternidade" como função principal da condição feminina, verificou-se neste estudo uma desvinculação predominante, que pode representar um processo de mudanças de comportamento e a quebra de paradigmas sociais e culturais entre os adolescentes (Pires, 2009). Os ideais contemporâneos associados à adolescência evidenciam que a gravidez/parentalidade não faz parte das perspectivas do adolescente, fato que está vinculado às profundas mudanças demográficas e ao acesso à informação no campo da sexualidade, redefinindo as expectativas sociais e familiares inerentes aos adolescentes (Brandão \& Heilborn, 2006). Entretanto, deve-se ressaltar que em camadas sociais menos favorecidas, a maternidade é bastante valorizada, possibilitando a afirmação de identidade, enquanto nas camadas sociais mais abastadas essa condição é quase inexistente (Canavarro et al., 2020).

Nesse estudo, quando analisadas o percentual de resposta para as dimensões, verificou-se uma percepção significativa de possível vínculo da maternidade como principal função feminina, podendo estar relacionada à vivência de responsabilidade parental pelo adolescente, visto que houve um percentual significativo para os adolescentes que não souberam opinar. Desse modo, dentre as variáveis que permaneceram no modelo, as maiores médias estão em os adolescentes possuírem dezoito/dezenove anos, serem do sexo masculino, estar cursando o segundo e terceiro ano do ensino médio, não ter companheiro e não viver com o mesmo, possuir trabalho remunerado, o mais baixo grau de instrução do chefe da família ( $\beta \mathrm{i}$ negativo) e menor renda familiar ( $\beta$ i negativo), corroborando com o estudo realizado em Ribeirão Preto-SP, com 200 adolescentes gravidas usuárias do SUS, identificando que a transição para a vida adulta foi o estabelecimento de vínculo com o parceiro e por consequência a maternidade (Vieira et al., 2017). Nesse mesmo estudo, verificou-se que as adolescentes eram predominantemente de classificação econômica "C", solteiras, viviam com o companheiro, e não estudavam, evidenciando que as mudanças do papel da mulher na sociedade ainda não chegaram a essa parcela de adolescentes (Vieira et al., 2017).

A maternidade adolescente do ponto de vista da saúde pública possui repercussões negativas, na medida em que implica em riscos para binômio mãe/bebê e risco de cuidados inadequados para ambos. Sob a perspectiva social, a gravidez na adolescência está relacionada à pobreza, à evasão escolar, aos subempregos e à baixa renda própria e de suas famílias (Dias \& Teixeira, 2010). Isso se intensifica se houver união conjugal, visto que mediante as responsabilidades do casamento e do filho, o adolescente não consegue prosseguir com os objetivos educacionais (Sousa \& Gomes, 2009).

Embora a percepção sobre a maternidade enquanto projeto de vida esteja em processo de mudança para os adolescentes, conforme resultados deste estudo, a gravidez/parentalidade ainda é uma realidade e um problema a ser enfrentado por meio de políticas públicas brasileiras, visto que sua ocorrência está associada às vulnerabilidades sociais e econômicas (Nery et al., 2015). Isso demostra falha nas políticas públicas, principalmente, de educação, evidenciando a estagnação das possibilidades de crescimento individual e social do indivíduo.

Outro fator importante que pode ser consequência de uma gravidez/parentalidade na adolescência é o abortamento induzido e inseguro, que segundo estudo (Urgellés et al., 2012), acontece na adolescência coincidindo com o início das relações sexuais. No presente estudo, as percepções predominantes dos adolescentes sobre o "aborto" foram negativas, o que pode estar relacionado ao senso comum, por respostas socialmente aceitáveis, visto que, o aborto é legitimado no Código Penal 
Brasileiro desde 1940 (Brasil, 1940). Assim, o grau de instrução do chefe da família apresentou associada a dimensão e a maior média encontra-se para o adolescente que tem o chefe da família analfabeto/fundamental I incompleto, evidenciando as piores percepções sobre o aborto e cada ano de estudo do chefe da família influencia o adolescente diminuindo a percepção negativa sobre o aborto.

A Pesquisa Nacional do Aborto (2016) mostrou que das 251 mulheres com idade entre 18 e 39 anos, que relataram ter realizado aborto induzido e inseguro, 29\% ocorreram na faixa etária entre 12 e 19 anos, mostrando frequência do último aborto na adolescência, sendo essas meninas de raça/cor parda, casadas, com ensino médio completo, trabalho remunerado e renda familiar de até dois salários mínimos (Diniz; Medeiros \& Madeiro, 2017). Apesar de não haver uma definição para os fatores socioeconômicos associados à percepção negativa sobre o aborto, neste estudo existe a predominância para as maiores médias nos fatores socioeconômicos mais baixos.

No entanto, o risco ao realizar um aborto está na forma como o mesmo vai proceder, visto que a situação econômica do indivíduo vai definir maior ou menor risco. Estudo conduzido em São Paulo com adolescentes verificou que a ocorrência do abortamento induzido e inseguro está associada a uma população com vulnerabilidades sociais e condições socioeconômicas precárias, além da falta de acesso à educação e da dificuldade de acesso aos serviços de saúde (Figueiredo et al., 2016).

No Brasil, o aborto induzido é rotineiramente condenado em público, discurso que ainda é praticado em larga escala. A World Values Survey (2010-2014), uma rede global de cientistas sociais que estudam a mudança de valores e seu impacto na vida social e política, realizou uma pesquisa com 1.500 brasileiros questionando sobre o aborto induzido ser justificável ou não. Mostrou que 69,9\% dos entrevistados acreditam que o aborto nunca é justificável, com esse percentual sendo maior entre os entrevistados na classe social mais baixa. Adolescentes amadurecendo em tal ambiente provavelmente vão ouvir informações conflitantes sobre o aborto. Assim, as percepções dos adolescentes provavelmente serão influenciadas pelas avaliações morais do aborto, articuladas por pares, mídia, família, educadores ou líderes religiosos (Steele, 2011).

Porém, a taxa de aborto no Brasil é alta, segundo Pesquisa Nacional de Aborto (PNA), estima-se que, em 2015, foram realizados aproximadamente 503 mil abortos por mulheres com idade entre 18 e 39 anos (Diniz; Medeiros \& Madeiro, 2017) e representando a quarta causa de morte materna em países em desenvolvimento, devido a complicações (Say et al., 2014). Aproximadamente 8\% das mortes maternas em todo o mundo são atribuídas ao aborto inseguro (McGovern, 2020). Segundo dados do relatório da OMS de 2012, estima-se que a cada ano no mundo sejam realizados três milhões de abortamentos induzidos e inseguros em adolescentes de 15 a 19 anos. Desse total, 16\% ocorrem na América Latina e Caribe.

Essas estimativas evidenciam um problema de saúde pública a ser enfrentado que está enraizado na vida reprodutiva das mulheres, respondendo de forma incisiva em como a sociedade brasileira considera a saúde sexual e reprodutiva no contexto biológico e social (Diniz; Medeiros \& Madeiro, 2017), situação que ainda permanece velada pela sociedade.

Portanto, além das características sociais deve-se considerar que as famílias exercem influência nas percepções dos adolescentes (Angelo et al. 2021). Porém, neste estudo, o fato dos adolescentes possuírem pais separados não influenciou nenhuma dimensão do QVCSMA, o que pode apresentar nessa amostra, apesar da maior proporção os pais não serem separados, que eles não estão exercendo influência sobre as percepções dos filhos em relação a saúde sexual e reprodutiva dos adolescentes.

O presente estudo trouxe contribuições relevantes pouco investigadas sobre percepção dos estudantes sobre sexualidade, maternidade e aborto e as associações com os fatores socioeconômicos e demográficos, mas apresenta limitações inerentes à representatividade dos alunos, visto que houve baixa adesão dos estudantes para participar da pesquisa. Contudo, o tamanho amostral foi expressivo, a forma de abordagem proporcionou privacidade, evitando potencial viés de informação. 


\section{Conclusão}

A percepção dos adolescentes sobre sexualidade, maternidade e aborto sofre influência dos fatores socioeconômicos, sendo as desigualdades sociais importante marcador dessas percepções e, consequentemente, dos comportamentos sexuais de risco. A sexualidade como dimensão do prazer é influenciada por condições sociais e econômicas favoráveis ao desenvolvimento do adolescente, evidenciando uma vivência responsável da atividade sexual. A sexualidade como dimensão da afetividade é característica da idade devido às transformações biopsicossociais na fase da adolescência e à imaturidade emocional. Quanto à sexualidade como função reprodutiva, esta é influenciada por condições socioeconômicas desfavoráveis, relacionadas a um contexto de maior vulnerabilidade social, apresentando fragilidade na vivência da sexualidade adolescente.

A desvinculação da maternidade como função principal da condição feminina representa um processo de mudanças de comportamento dos adolescentes, e também, é influenciada por condições sociais e econômicas favoráveis ao desenvolvimento do adolescente. Quanto ao aborto, as percepções dos adolescentes foram negativas, apresentando as piores percepções sobre o tema, o que pode ser influenciado provavelmente pelas avaliações morais do aborto, que são difundidas em larga escala na sociedade brasileira, e relacionadas às condições de maior vulnerabilidade social, representado uma situação velada pela sociedade.

Nesse sentido, há necessidade de se ampliar as estratégias de atuação dos profissionais de educação e saúde, considerando as individualidades do adolescente, trabalhando com metodologias diferenciadas, buscando orientá-los, envolvendo nesse diálogo, além do adolescente, os pais, para fortalecer e atuar em conjunto, empoderando o adolescente sobre sua sexualidade e promovendo a saúde sexual.

\section{Agradecimentos}

À Secretaria Estadual de Educação do Estado do Espírito Santo pela viabilização da coleta de dados no ensino médio.

À Fundação de Amparo à Pesquisa e Inovação do Espírito Santo (FAPES) pelo financiamento do projeto do EDITAL UNIVERSAL FAPES Nº07/2014 - PROJETO INTEGRADO DE PESQUISA.

\section{Referências}

Ahman, E., \& Shah, I. H. (2011). New estimates and trends regarding unsafe abortion mortality. International Journal of Gynaecology and Obstetrics, 115(2):121-126.

Ahorlu, C. K., Pfeiffer, C., \& Obrist, B. (2015). Socio-cultural and economic factors influencing adolescents' resilience against the threat of teenage pregnancy: a cross-sectional survey in Accra, Ghana. Reproductive Health, 12 (117):1-12.

Angelo, L. K. G., Silva, C. L. A., Bernardino, A. C., Silva, C. A. A., Candido, S. A., Pacheco, A. L. D., Melo, I. S., \& Castro, O.W. (2021). Influência familiar e de outras fontes de informações na construção dos conhecimentos dos adolescentes acerca da sexualidade. Brazilian Journal of Development, 7(2):2043320444.

Aquino, E. M. L., Heilborn, M. L., Knauth, D., Bozon, M., Almeida, M. C., Araújo, J., \& Menezes, G. (2003). Adolescência e reprodução no Brasil: a heterogeneidade dos perfis sociais. Cadernos de Saúde Pública, 19 (supl. 2):S377-S388.

Arán, M. (2003). Os destinos da diferença sexual na cultura contemporânea. Revista Estudos Feministas, 11(2):399-422.

Beserra, E. P., Sousa, L. B., Cardoso, V. P., \& Alves, M. D. S. (2017). Perception of adolescents about the life activity "express sexuality". Revista de Pesquisa: Cuidado é Fundamental Online, 9(2):340-346.

Brandão, E. R., \& Heilborn, M. L. (2006). Sexualidade e gravidez na adolescência entre jovens de camadas médias do Rio de Janeiro. Cadernos de Saúde Pública, 22(7):1421-1430.

Brasil. (1940). Presidência da República. Casa Civil - Subchefia para Assuntos Jurídicos. Código Penal Brasileiro. Decreto-lei 2.848/1940. http://legislacao.planalto.gov.br/legisla/legislacao.nsf/Viw_Identificacao/DEL202.848-1940?OpenDocument. (acessado em jul/2017).

Brasil. (2006). Secretaria de Atenção à Saúde. HIV/Aids, hepatites e outras DST. Cadernos de Atenção Básica. Departamento de IST/AIDS. Brasília - DF. 18. Breuner, C. C., \& Mattson, G. (2016). Sexuality Education for Children and Adolescents. Pediatrics, 138:e20161348. 
Canavarro, M. C., Silva, N., Diniz, E., Pereira, M., Koller, S. H., \& Pires, R. (2020). Sociodemographic, sexual, and reproductive variables associated with pregnancy among adolescents from low socioeconomic background. J Community Psychol. 2020;1-19. https://doi.org/10.1002/jcop.22364

Carvalho, A. M., Rodrigues, C. S., \& Medrado, K. S. (2005). Oficinas em sexualidade humana com adolescentes. Estudos de Psicologia, 10(3):377-84.

Carvalho, A. I. (2013). Determinantes sociais, econômicos e ambientais da saúde. In: Fundação Oswaldo Cruz. A saúde no Brasil em 2030 - prospecção estratégica do sistema de saúde brasileiro: população e perfil sanitário [online]. Fiocruz/Ipea/ministério da saúde/secretaria de assuntos estratégicos da presidência da república. 19-38. http://books.scielo.org.

Carvalho, C. P., Pinheiro, M. R. M., Gouveia, J. A., Vilar, D. (2016). Attitudes and Beliefs Questionnaire about Sexuality and Sexual Education (ABQSSE) for adolescents: psychometric validation studies. Journal of Child and Adolescent Psychology, 7 (1-2):345-363.

Chandra-Mouli, V., Svanemyr, J., Amin, A., Fogstad, H., Say, L., Girard, F., \& Temmerman, M. (2015). Twenty Years After International Conference on Population and Development: Where Are We With Adolescent Sexual and Reproductive Health and Rights? Journal of Adolescent Health, 56:S1-S6.

Dias, A. C. G., \& Teixeira, M. A. P. (2010). Gravidez na adolescência: um olhar sobre um fenômeno complexo. Paidéia, $20(45): 123-131$.

Diniz, D., Medeiros, M., \& Madeiro, A. (2017). Pesquisa Nacional de Aborto 2016. Ciência \& Saúde Coletiva, 22(2):653-660.

Figueiredo, R., Kalckmann, S., Rosa, T. E. C., \& Venâncio, S. I. (2016). Gravidez na adolescência e abortos provocados: efetividade da Estratégia de Saúde da Família em eventos de saúde reprodutiva. Boletim do Instituto de Saúde, 17(2):19-28.

Fontenberry, J. D. (2013). Puberty and Adolescent Sexuality. Hormones and Behavior, 64(2):280-287.

Heilborn, M. L., Aquino, E. M. L., Bozon, M., \& Knauth, D. (2006). O aprendizado da sexualidade: reprodução e trajetórias sociais de jovens brasileiros, editora Fiocruz - Garamond.

McGovern, T. (2020). US Global Gag Rule increases unsafe abortion. Lancet, 396(10243):24-25. 10.1016/S0140-6736(20)30921-1.

Nery, I. S., Gomes, K. R. O., Barros, I. C., Gomes, I. S., Fernandes, A. C. N., \& Viana, L. M. M. (2015). Fatores associados à reincidência de gravidez após gestação na adolescência no Piauí, Brasil. Epidemiologia e Serviços de Saúde, 24(4):671-680.

Oliveira-Campos, M., Nunes, M. L., Madeira, F. C., Santos, M. G., Bregmann, S. R., Malta, D. C., \& Barreto, S. M. (2014). Comportamento sexual em adolescentes brasileiros, pesquisa nacional de saúde do escolar (PENSE 2012). Revista Brasileira de Epidemiologia, 17 (supl. 1):116-130.

Organización Mundial de la Salud (2012). Prevenir elembarazo precoz y los resultados reproductivos adversos en adolescentes en los países en desarrollo: las evidencias. Departmento de salud materna, del reciénnacido, del niño y el adolescente. www.who.int/maternal_child_adolescent/es/.

Pereira, A.I. L. F. (2016). Contextos relacionais de vulnerabilidade e proteção para a gravidez na adolescência. [Dissertação]. Coimbra: Universidade de Coimbra.

Pires, R. S. A. (2009). Contributo para a compreensão da etiologia e impacto da gravidez na adolescência: A influência de variáveis sociodemográficas e de variáveis relacionais, passadas e presentes, no ajustamento socioemocional de um grupo de grávidas adolescentes. [dissertação]. Coimbra. Universidade de Coimbra - Faculdade de Psicologia e de Ciências da Educação.

Say, L., Chou, D., Gemmill, A., Tunçalp, O., Moller, A. B., Daniels, J., \& Alkema, L. (2014). Global causes of maternal death: a WHO systematic analysis. Lancet Global Health, 2:e323-33.

Sereno, S., Leal, I., \& Maroco, J. (2009). Construção e validação de um questionário de valores e crenças sobre Sexualidade, Maternidade e Aborto. Psicologia, Saúde \& Doenças, 10(2):193-204.

Sereno, S., Leal, I., \& Maroco, J. (2013). The Role of Psychological Adjustment in the Decision Making Process for Voluntary Termination of Pregnancy. Journal of Reproduction \& Infertility, 14(3):143-151.

Silva, A. S. N., Silva, B. L. C. N., Silva Júnior, A. F., Silva, M. C. F., Guerreiro, J. F., \& Sousa, A. S. C. A. (2015). Início da vida sexual em adolescentes escolares: um estudo transversal sobre comportamento sexual de risco em Abaetetuba, Estado do Pará, Brasil. Revista Pan-Amazônica de Saúde, 6:27-34.

Sousa, M. C. R., \& Gomes, K. R. O. (2009). Conhecimento objetivo e percebido sobre contraceptivos hormonais orais entre adolescentes com antecedentes gestacionais. Cadernos de Saúde Pública, 25(3):645-654.

Steele, L. G. (2011). A Gift from God: Adolescent Motherhood and Religion in Brazilian Favelas. Sociology of Religion, 72(1):4-27.

UNICEF (2015). The United Nations Children's Fundation. Early Marriage a Harmful Traditional Practice. A Statistical Exploration. https://www.unicef.org/publications/files/Early_Marriage_12.lo.pdf.

United Nations Educational, Scientific and Cultural Organization (2010). Orientação Técnica Internacional sobre Educação em Sexualidade: Uma abordagem baseada em evidências para escolas, professores e educadores em saúde. (razões em favor da educação em sexualidade). $\mathrm{http} / /$ :unesdoc.unesco.org/mwg-internal/de5fs23hu73ds/progress?id=.

Urgellés Carrera, S. A., Reyes Guerrero, E., Figueroa Mendoza, M., \& Batán Bermúdez, Y. (2012). Comportamiento sexual y aborto provocado en adolescentes y jóvenes de escuelas de educación superior. Revista Cubana de Obstetricia y Ginecología, 38: 549-557.

Vieira, E. M., Bousquat, A., Barros, C. R. S., \& Alves, M. C. G. P. (2017). Gravidez na adolescência e transição para a vida adulta em jovens usuárias do SUS. Revista de Saúde Pública, 51: 25.

World Values Survey V204.- Please tell me for each of the following actions whether you think it can always be justified, never be justified, or something in between: Abortion. https://www.cms.fss.ulaval.ca/upload/pol/fichiers/wv5_questionnaire_splitversion_non_oecd.pdf. 